\title{
Effect of Irradiation and Temperature on Microstructural Characteristic of FeCrAl Alloys
}

\author{
I. Voiculescu ${ }^{a}$, V. Geanta ${ }^{a}$, E.M. Stanciu ${ }^{b}$, D.A. Jianu ${ }^{c}$, C. Postolache ${ }^{d}$, V. Fugaru ${ }^{d, *}$ \\ ${ }^{a}$ Polytehnic University, Bucharest, Romania \\ ${ }^{b}$ University of Transilvania, Braşov, Romania \\ ${ }^{c}$ Karslruhe Institute of Technology, Karlsruhe, Germany \\ ${ }^{d}$ Horia Hulubei National Institute for Physic and Nuclear Engineering, Romania
}

\begin{abstract}
Characteristics of $\mathrm{FeCrAl}$ alloys family are currently investigated in order to determine their behavior in different types of environment, erosive and corrosive (solid, liquid or gaseous), at high temperatures $\left(400-1000^{\circ} \mathrm{C}\right.$ ). The application with a special impact of these alloys consists in their use to build structural components of nuclear power plant (IV generation) at which the cooling medium is made of liquid metal with very high heat transfer capacity ( $\mathrm{Pb}, \mathrm{Pb}-\mathrm{Bi}, \mathrm{Sn}$ etc). To improve the resistance in extreme conditions (corrosion, erosion, high temperature) of the alloy, a superficial oxide layer may be formed, which constitutes an effective barrier against the destructive action of the working environment. This paper presents some results obtained regarding the influence of gamma irradiation on a FeCrAl alloy surface, after the sample surface was superficially remelted by laser and maintained in molten lead in furnace at $500^{\circ} \mathrm{C}$ for 6 to 12 months. Metallographic aspects, such as microstructural changes, layer thicknesses and homogeneity are analyzed. New compounds formed after irradiation using Co-60 gamma rays are investigated.
\end{abstract}

DOI: 10.12693/APhysPolA.134.116

PACS/topics: FeCrAl alloys, oxide layer, irradiation, microstructure

\section{Introduction}

Alloys from the class of $\mathrm{FeCrAl}$ are characterized by excellent mechanical and corrosion resistance at high temperatures $\left(800-1000^{\circ} \mathrm{C}\right)$ and are usually used for engine components or resistive elements for electric furnaces [1], car parts, etc. [2].

A very important domain where these alloys can be used is that of modern $4 \mathrm{R}$ nuclear reactors. In this specific case, the materials used for the reactor and the circulating cooling system must have special mechanical and thermo-physical characteristics such as high resistance to corrosion and erosion in the molten metal environment, resulting from the specific operating conditions $[2,3]$.

$\mathrm{FeCrAl}$ grade steels have high corrosion and oxidation resistance by forming a chemically resistant and passive chromium oxide layer $[3,4]$. In order to improve the resistance to high temperatures in the molten lead environment, a composite structure can also be created at the surface level by depositing a thin alumina layer (plasma spray deposition or laser cladding with powder) which will be then remelted using electron beam or laser processing, for creating a very adherent metalo-ceramic layer $[5,6]$.

This paper presents a series of results regarding the behavior of $\mathrm{FeCrAl}$ alloys maintained in molten lead at $500{ }^{\circ} \mathrm{C}$ for 6 to 12 months and after irradiation with Co60 gamma rays. The effects of laser processing on the formation of oxide layers and the accumulation tendency

*corresponding author; e-mail: vfugaru@nipne.ro of micro alloying elements in the remelted areas are highlighted. The immersion in molten lead has determined the diffusion of lead through the grain boundaries of the ferrite matrix alloyed with $\mathrm{Cr}$ and the dissolution of oxide layer.

\section{Materials and processing methods \\ 2.1. Preparation of $\mathrm{FeCrAl}$ alloys}

The samples were designed and manufactured in the ERAMET laboratory, at the Polytechnic University of Bucharest, at faculty of Material Science and Engineering, using a MRF ABJ 900 furnace. Experimental $\mathrm{FeCrAl}$ alloys were obtained, with different contents of zirconium (2.5 wt.\%) and yttrium (1.25 wt.\%) added into the same metallic matrix of the $\mathrm{Fe} 16 \mathrm{Cr} 8 \mathrm{Al}$ experimental alloy.

After obtaining the stable vacuum of $1 \times 10^{-4} \mathrm{mBar}$, the furnace chamber was filled with argon (Ar $5.3 \mathrm{pu}-$ rity) to ensure the stability of electric arc. Each miniingot was remolten and solidified six times, in order to obtain the microstructural homogeneity. FeCrAl alloys were processed at dimensions of $30 \times 10 \times 6 \mathrm{~mm}^{3}$, then superficially laser treated on one side. The heating source used for the superficial processing/remelting of the samples was a $1 \mathrm{~kW}$ continuous wave diode laser. The melted bath protection was ensured by argon gas coaxially provided at a flow rate of $6 \mathrm{l} / \mathrm{min}$ (Fig. 1).

Subsequently the samples were continuously kept in lead baths melted at $500{ }^{\circ} \mathrm{C}$ for different periods $(6$ to 12 months of immersion) and then exposed to a high gamma field produced by a Co-60 source (dose rate of $310 \mathrm{~Gy} / \mathrm{h}$, with the total dose of $0.3 \mathrm{MGy}$ ), in order to analyse their corrosion resistance and erosion effect on superficial oxide layer. 


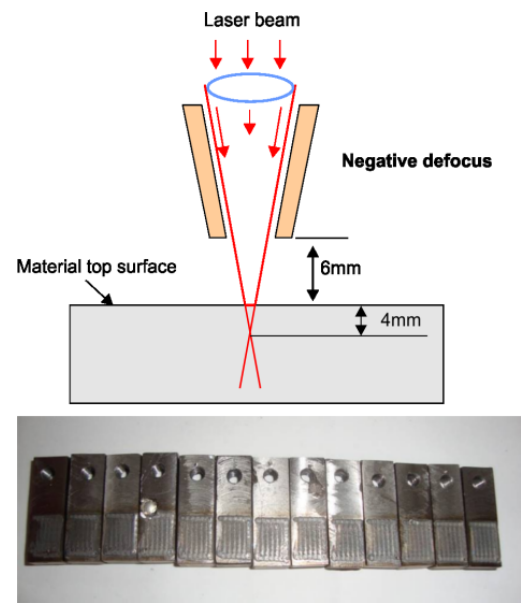

Fig. 1. Schematic of the laser remelting process and samples after laser processing.

\subsection{Microstructural analysis}

The microstructural analysis was conducted using a scanning electron microscope FEI QUANTA INSPECT F provided with an electron gun with field emission, with a resolution of $1.2 \mathrm{~nm}$ and using X-ray energy dispersive spectrometer (EDS) with resolution of $133 \mathrm{eV}$ at MnK.

Each cross section cut from the mini-ingots was processed according to the metallographic procedure using abrasive grit paper, followed by a final polishing using alumina alpha powder. In as-casting state, the alloy contains dendritic microstructures, with inter-dendritic eutectic, rich in alloying elements $\mathrm{Cr}, \mathrm{Al}, \mathrm{Zr}$ and $\mathrm{Y}$ (Fig. 2a). There are small areas rich in micro-alloying elements of $\mathrm{Zr}$ and $\mathrm{Y}$, disposed on the eutectic (Fig. 2b, points 1, 2 and 3).
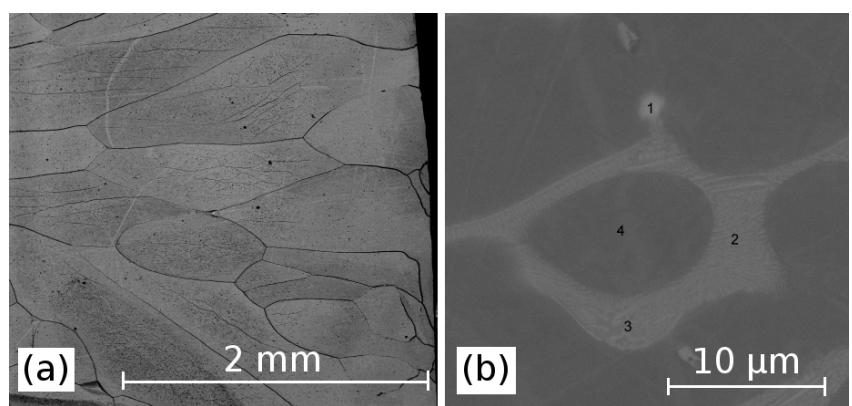

Fig. 2. Microstructure of as-cast FeCrAl alloy and detail on the Zr- and Y-rich eutectic.

Chemical composition (at.\%) for points shown in Fig. 2 is: $28.68 \mathrm{Zr}, 4.73 \mathrm{Y}, 12.33 \mathrm{Cr}, 5.31 \mathrm{Al}, 48.96 \mathrm{Fe}$ for point 1 ; $10.85 \mathrm{Zr}, 7.26 \mathrm{Y}, 11.15 \mathrm{Cr}, 7.94 \mathrm{Al}, 62.8 \mathrm{Fe}$ for point 2 ; $9.93 \mathrm{Zr}, 3.54 \mathrm{Y}, 12.25 \mathrm{Cr}, 8.64 \mathrm{Al}, 65.64 \mathrm{Fe}$ for point 3 ; and $18.02 \mathrm{Cr}, 7.7 \mathrm{Al}, 74.29 \mathrm{Fe}$ for point 4 . Point 4 has the typical chemical composition of $\mathrm{FeCrAl}$ alloy without microalloying elements.
Superficial laser remelting led to the formation of an uniform and compact layer, in which the intermetallic precipitates have been dissolved into the basic matrix (Fig. 3a). The depth of penetration was between 370-458 $\mu \mathrm{m}$. Laser irradiation resulted in a fine dendritic microstructure, while maintaining the hereditary grain boundaries (Fig. 3b) and dissolving the microprecipitates. Unfortunately, high cooling rates during laser processing have generated a network of microcracks at the surface of the treated samples, which affected their resistance to the action of molten lead (Fig. 4).
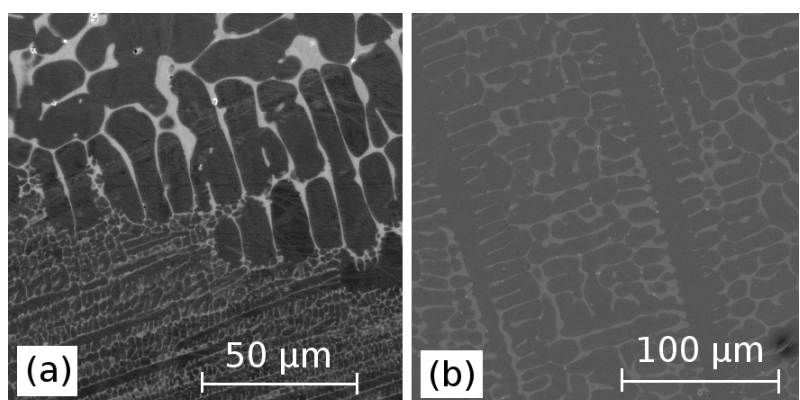

Fig. 3. Interface between the base matrix and laser remelted zones for $\mathrm{Fe} 16 \mathrm{Cr} 8 \mathrm{Al} 2.5 \mathrm{Zr} 1.25 \mathrm{Y}$ alloy.

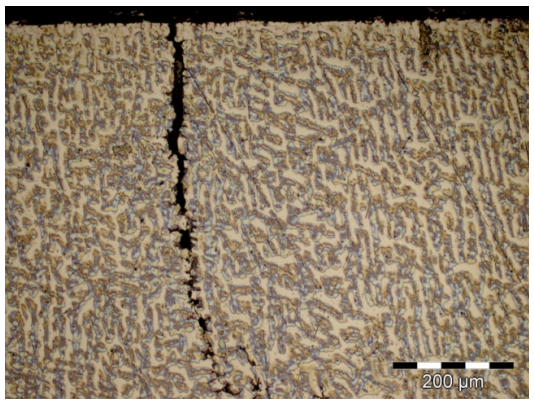

Fig. 4. Micro-cracks developed in the laser processed layer.

\section{Results and discussion}

Long-term contact with molten lead has led to the formation of a lead-adherent crust on the surface of the samples without producing a total dissolution of the complex oxide protective layer, consisting of alumina and zirconia (Fig. 5).

An undesirable effect of the subjection to molten lead appears to be the formation of pores in the proximity of the laser-treated layer. The pores come from the working environment, the argon flow used being insufficient to ensure an optimal protection of the molten metal (Fig. 5a).

The chemical composition (at.\%) of the oxide-rich crust was measured in three points, as follows: $23.9 \mathrm{~Pb}$, $11.57 \mathrm{Cr}, 7.58 \mathrm{Al}, 10.24 \mathrm{O}, 46.72 \mathrm{Fe}$ at point $1 ; 65.15 \mathrm{~Pb}$, $0.26 \mathrm{Cr}, 6.4 \mathrm{Al}, 27.25 \mathrm{O}, 0.92 \mathrm{Fe}$ at point $2 ; 59.85 \mathrm{~Pb}$, $0.43 \mathrm{Cr}, 8.23 \mathrm{Al}, 30.48 \mathrm{O}, 1 \mathrm{Fe}$ at point 3 . The thickness of the oxide layer, partially dissolved by long-lasting immersion time in lead is between 4 and 8 microns (Fig. 5b). 

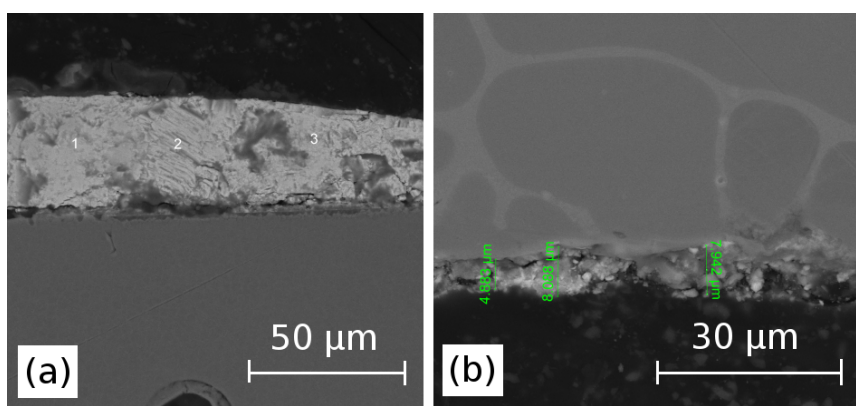

Fig. 5. Cross section microstructure of the Fe16Cr8Al2.5Zr1.25Y alloy after immersion for 85 days into the $\mathrm{Pb}$ medium melted at $500{ }^{\circ} \mathrm{C}$.

Some chemical elements $(\mathrm{Cr}, \mathrm{Al})$ have diffused into leadrich oxide crust, which testifies to the undesirable effect of long-term maintenance in the test environment.

The surfaces that have not been laser-treated are not obviously affected by the lead penetration, under the same working conditions (Fig. 6a). The effects of lead diffusion at the surface of the alloy was assesed by chemical composition analyzes, which were performed along a line perpendicular to the surface (Fig. 6a, points 1, 2 and 3). It was found that $\mathrm{Pb}$ is found only at the level of point $1(11.76$ at.\% $\mathrm{Pb})$ and point $2(3.15$ at.\% $\mathrm{Pb})$, located at a depth of about 25 microns from the sample surface. At a greater depth of about 50 microns (point 3, Fig. 6a), $\mathrm{Pb}$ was not detected in the chemical composition of the metal.
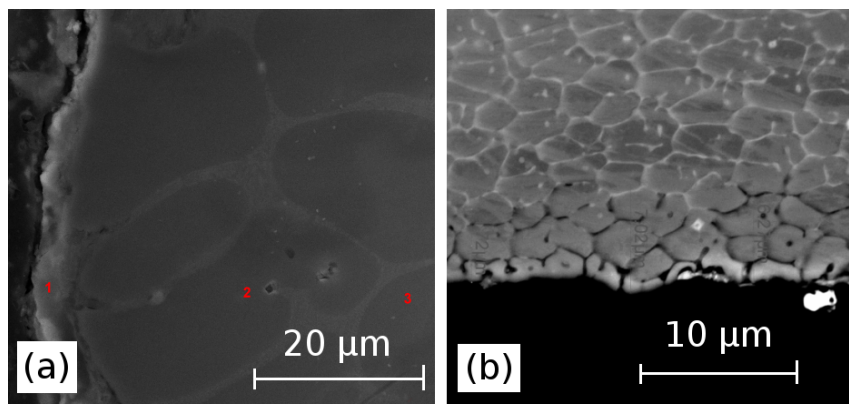

Fig. 6. Cross section microstructure of the Fe16Cr8Al2.5Zr1.25Y alloy after maintaining in melted $\mathrm{Pb}$ at $500{ }^{\circ} \mathrm{C}$ for 48 days and irradiation: (a) surface without laser processing; (b) laser remelted surface.

In the case of laser processed layer (Fig. 6b), as a result of long maintenance in the molten metal environment, there is a tendency to dissolve the oxide-ceramic layer at the interface with the working environment, and a tendency of penetration of the reaction products through the grain boundaries.

As a result of irradiation with Co-60 gamma rays the diffusion effect is increased. After a long period of immersion $\left(12\right.$ months at $\left.500^{\circ} \mathrm{C}\right), \mathrm{Pb}$ has dissolved the ceramicoxide layer and penetrated through the grain boundary (Fig. 7). To assess the erosion effects in the superficial ox- ide layer, local micro-chemical analyzes were performed on the oxide crusts. In these areas, the tendency to form complex compounds containing alloying elements such as $\mathrm{Al}, \mathrm{Cr}, \mathrm{Zr}$ and $\mathrm{Y}$ has been observed.

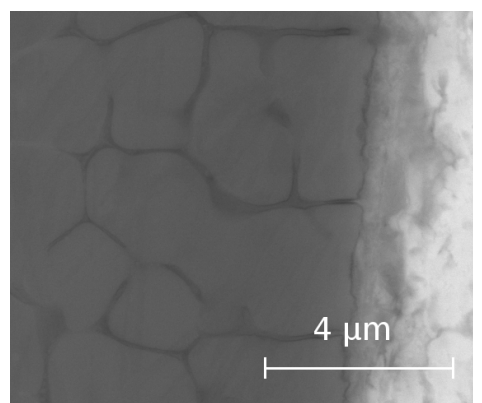

Fig. 7. $\mathrm{Pb}$ diffusion on grain boundaries after immersion for 12 months at $500{ }^{\circ} \mathrm{C}$.

\section{Conclusions}

By superficial laser processing of the Fe16Cr8Al2.5Zr1.25Y alloy, granulation finishing and a uniform layout of the micro-alloying elements in the remelted area were obtained. However, as a result of high cooling rates and insufficient argon protection, pores and micro-cracks have appeared in the laser-remelted surfaces. The complex oxide layer present on the sample surfaces contains, besides the elements of the metal matrix $(\mathrm{Fe}, \mathrm{Cr}, \mathrm{Al})$, some microalloying elements ( $\mathrm{Zr}$ and $\mathrm{Y}$ ), as well as $\mathrm{Pb}$. The harmful effects of lead reveal themselves by the gradual dissolution of the thin oxide layer (having 1-2 $\mu \mathrm{m}$ thickness) that protects the metal matrix. The irradiation of the sample can enhance the penetration of lead through the grain boundaries, which decreases the corrosion resistance of the material. Laser processing of alloy surfaces causes an increase of sensitization to the molten lead diffusion at grain boundaries.

\section{Acknowledgments}

The research was financially supported by the Romanian National Program for Research within the framework of the Project No. PCCA 243/2014 Advanced Metallic Materials Used for the New Generation of Nuclear Power Plant 4R - NUCLEARMAT.

\section{References}

[1] D. Ugues, S. Specchia, G. Saracco, Ind. Eng. Chem. Res. 43, 1990 (2004).

[2] V. Geantă, I. Voiculescu, R. Ştefănoiu, A. Jianu, Metalurgia International XVI, 153 (2011).

[3] V. Geanta, I. Voiculescu, E.-M. Stanciu, IOP Conf. Ser.: Mater. Sci. Eng. 133, 012016 (2016).

[4] T.R. Allen, D.C. Crawford, Science and Technology of Nuclear Installations 2007, 97486 (2007).

[5] J.L. Ocańa, M. Morales, C. Molpeceres, J.A. Porro, AIP Conference Proceedings 1278, 902 (2010).

[6] A. Pascu, E.M. Stanciu, I. Voiculescu, M.H. Tierean, I.C. Roata, J.L. Ocana, Materials and Manufacturing Process 31, 311 (2016). 